Physical-

\section{Physical \& Occupational Therapy In Pediatrics}

\title{
Decisional Support Algorithm for Collaborative Care Planning using the Participation and Environment Measure for Children and Youth (PEM-CY): A Mixed Methods Study
}

Mary A. Khetani, Anna B. Cliff, Cathy Schelly, Lisa Daunhauer \& Dana Anaby

To cite this article: Mary A. Khetani, Anna B. Cliff, Cathy Schelly, Lisa Daunhauer \& Dana Anaby (2015) Decisional Support Algorithm for Collaborative Care Planning using the Participation and Environment Measure for Children and Youth (PEM-CY): A Mixed Methods Study, Physical \& Occupational Therapy In Pediatrics, 35:3, 231-252, DOI: 10.3109/01942638.2014.899288

To link to this article: https://doi.org/10.3109/01942638.2014.899288

Published online: 26 Mar 2014.

Џ Article views: 473
Submit your article to this journal $₫$ 


\title{
Decisional Support Algorithm for Collaborative Care Planning using the Participation and Environment Measure for Children and Youth (PEM-CY): A Mixed Methods Study
}

\author{
Mary A. Khetani ${ }^{1}$, Anna B. Cliff ${ }^{1}$, Cathy Schelly ${ }^{1}$, Lisa Daunhauer ${ }^{2}$, \\ $\&$ Dana Anaby ${ }^{3}$
}

${ }^{I}$ Department of Occupational Therapy, Colorado State University, Fort Collins, CO, USA, ${ }^{2}$ Department of Human Development and Family Studies, Colorado State University, Fort Collins, CO, USA, ${ }^{3}$ School of Physical and Occupational Therapy, McGill University, Montreal, Quebec, Canada

\begin{abstract}
Aims: The purpose of this study was to explore the utility of the Participation and Environment Measure for Children and Youth (PEM-CY) for collaborative care planning with parents of children with disabilities. Methods: An explanatory sequential mixed methods approach was employed to examine how community-based service providers interpret and apply PEM-CY case results to set goals and formulate care plans with parents. We used two distinct, interactive phases that included collection and summary of PEM-CY data in Phase One (quantitative) and sequential collection and analysis of interview data during Phase Two (qualitative). Twenty-three parents of children with disabilities (mean age $=10.7$ years) completed the PEM-CY community section during Phase One (quan). Four PEM-CY case reports were used with seven providers who were interviewed during Phase Two (QUAL). Results: Providers identified a four-step decisional support algorithm for leveraging PEM-CY case results in care planning: (1) parent rank orders activities in which change is desired, (2) child preferences are incorporated, (3) provider clarifies parent and child goals, and (4) activityspecific supports, barriers, and strategies are identified. Conclusions: Further validation and refinement of the decisional support algorithm with parents and children when applied to PEM-CY home and school reports is discussed.
\end{abstract}

KEYWORDS: Children, disability, family-centered, participation, planning, youth

Children's participation in everyday activities is an internationally recognized indicator of their health and well-being (UNICEF, 2013; WHO, 2007; WHO and World Bank, 2011) and fundamental human right for children regardless of their age, background, or disability (United Nations, 2006). Greater participation is linked

Address correspondence to: Mary A. Khetani, Department of Occupational Therapy, 222 Occupational Therapy Building, Fort Collins, CO 80523-1573, USA (E-mail: mary.khetani@colostate.edu).

(Received 26 November 2013; accepted 13 February 2014) 
to positive development since through participation in different activity contexts, children gather knowledge and skills needed to live, play, work, and learn (Dunst et al., 2002; Rogoff, 2003; Tseng \& Seidman, 2007). Children with disabilities experience greater participation restriction than their peers without disabilities (Barnett, 2012; King et al., 2013; Law et al., 2007; Verschuren et al., 2013). Minimizing this disparity is a top research priority for parents, placed second only to the need for knowledge on preventing the child's health condition (McIntyre et al., 2010).

Children's participation is a multidimensional concept (Coster \& Khetani, 2008; Whiteneck \& Dijkers, 2009) and is affected by child factors (e.g., age, gender, functional abilities), family factors (e.g., parental education, household income), physical, social, cultural, and temporal features of environments (Bronfenbrenner, 1997; Kramer \& Hammel, 2011) and ways that activities are organized (Law et al., 1996). Given its complexity, there is a critical need for more comprehensive, detailed, and feasible assessment of children's participation as an outcome for large-scale outcomes research, program assessment, and group and individual level intervention planning (Bedell \& Coster, 2008).

The Participation and Environment Measure for Children and Youth (PEMCY) was developed to help advance knowledge about children's participation in large-scale research studies involving children with and without disabilities. The PEM-CY is the first online parent-report survey for gathering information about both the child's participation and environmental impact on participation in home, school, and community settings. Analyses of data from the PEM-CY validation study suggest that it can detect significant differences between children with and without disabilities for each setting in terms of participation frequency, extent of involvement, desire for change, and environmental supportiveness at both the summary and item-level, even when controlling for the child's age, gender, and/or household income (Bedell et al., 2012; Coster et al., 2012; Law et al., 2013).

The PEM-CY may yield relevant information to inform the development of an intervention plan, either at the group (Khetani et al., 2013) or individual level. By design, the PEM-CY yields information about (1) specific home, school, and community-based activities in which the child is perceived to experience participation restriction, (2) parent perceptions of environmental factors that may contribute to participation restriction in a specific setting, and (3) parent strategies to promote participation in a specific setting. Hence, information generated from the PEM-CY may assist service providers and parents in (1) prioritizing areas of participation restriction warranting intervention, and (2) identifying modifiable environmental factors for improving a child's participation in a specific activity. The uptake of the PEM-CY in clinical practice hinges on providers being able to administer the PEM-CY, interpret survey results, and apply those results to develop a care plan in collaboration with children and families.

The purpose of this study is to examine the utility of the PEM-CY for collaborative care planning with individual families of children and youth with disabilities. A mixed-methods explanatory sequential approach was employed to answer the following research questions:

Phase 1 (quan) Research Questions: (1) In what types of community activities do parents most often desire change in their children's participation? (2) Which 
community environment features do most parents perceive to support and challenge children's community participation?

Phase 2 (QUAL) Research Question: For children who are enrolled in community-based services to promote their inclusion, how can staff use the PEMCY case report for care planning?

Mixed Methods Question (quan > QUAL): What are staff perceptions of the key advantages and disadvantages of the PEM-CY for care planning relative to their usual process of care?

\section{METHODS}

This study involved collaboration with a community-based service agency that is funded by [location held for review] to promote full community inclusion of children and youth with disabilities in [location held for review]. Institutional Review Board approval was obtained to conduct a mixed methods study using an explanatory sequential design (Creswell \& Clark, 2011). This study design was chosen because analyses of parent responses on the PEM-CY were expected to be necessary but insufficient for addressing the main study aim of understanding the utility of the PEM-CY for collaborative care planning. We first summarized PEM-CY data on a subsample of agency clients in the quantitative phase of the study (quan) to better understand patterns of community participation restriction and environmental supports and barriers to community participation. In the second qualitative phase of study (QUAL), PEM-CY case reports were shared with agency staff (e.g., supervisors, coordinators, class leaders) to understand how they interpret and apply PEM-CY for collaborative care planning with families. A brief summary of the overall study design is shown in Figure 1, with shorthand notation (quan, QUAL, quan $>$ QUAL) being used to convey the priority and sequence of each method.

\section{Phase 1: Quantitative Component}

\section{Sample}

Using a cross-sectional design, eligible participants met these criteria: (1) able to read and write in English, (2) identify as a parent or legal guardian of a child with a developmental delay or disability, (3) have a child ages 5 to 17 years old, (4) reside in [location held for review] or the surrounding area, and (5) have enrolled in agency services to support their child's community participation. Participants were recruited at special events, outreach activities, classes (e.g., swimming), and through electronic newsletters and mailings. Purposeful sampling methods were used to obtain the perspectives of a diverse sample of clients according to the child's gender, age, disability status, and number of functional limitations (Creswell, 2007).

\section{Measures}

Two surveys were administered to participants during Phase One (quan) of this study. 
Phase One: Quantitative (quan)

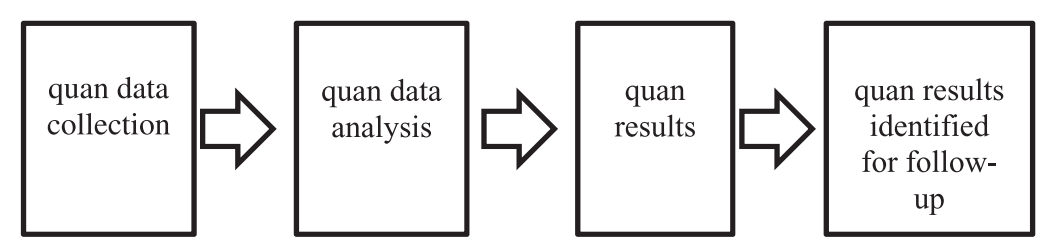

Phase Two Qualitative (QUAL)

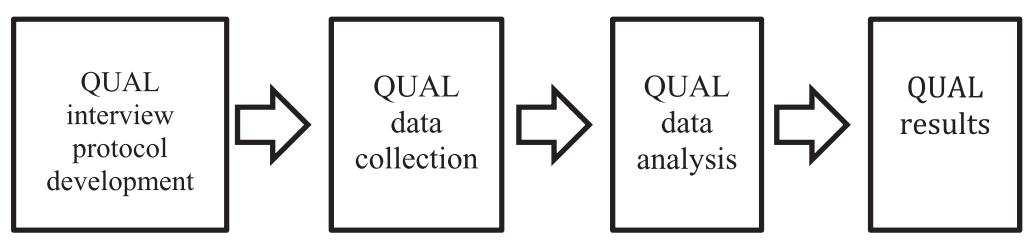

\section{Interpretation \\ quan --> QUAL}

FIGURE 1. Mixed methods sequential explanatory design. Figure adapted from Creswell \& Clark, 2011.

\section{Demographic Questionnaire}

The demographic questionnaire contained items related to (1) family factors (e.g., marital status, annual income, respondent education) and (2) child factors (e.g., diagnosis, functional problems [e.g., paying attention], school placement, adaptive equipment use). For selection of PEM-CY case reports for Phase Two (QUAL) data collection, we identified the most commonly reported areas of functional difficulty by summing the number of participants who indicated their child as having a "little problem" or "big problem" with each of 11 functional problems (3-point scale, from no problem (1) to big problem (3)).

\section{Participation and Environment Measure for Children and Youth (PEM-CY)}

The 25-item PEM-CY assesses a child's participation in broad types of activities in the home (10 items), school (5 items), and community (10 items). For each item, participants assess three dimensions of their child's participation: (1) frequency (8-point scale from never [0] to daily [7]); (2) level of involvement (5-point scale from minimally involved [1] to very involved [5]); and (3) their desire for change in the child's participation (yes or no; if yes, is change desired for frequency, level of involvement, and/or involvement in a broader variety of activities of that type). After completing participation items for a setting, parents evaluate the impact of environmental features or resources on their child's participation. To assess the 
impact of environmental features on participation, the following response options are used: (1) not an issue/usually helps, (2) sometimes helps, sometimes makes harder, and (3) usually makes harder. To assess the impact of resource availability on participation, the following response options are used: (1) not needed/usually yes, (2) sometimes yes, sometimes no, and (3) usually no.

For the first two Phase One (quan) research questions, the following PEM-CY summary scores were calculated based on responses to items within the PEM-CY community section: (1) percent desire change in community activities (sum of "yes, desire change" responses for each individual child, divided by 10 items, and multiplied by 100 to generate an individual percent change score, then calculate the average percent across all children sampled), and (2) the percentage of parents who desired change in their child's participation for each community activity (sum of $\%$ yes, desire change responses for each item, divided by total number of parents sampled and multiplied by 100). For the third Phase One (quan) research question, we calculated (1) number of supports (sum of "usually helps" or "usually, yes" responses for each item), and (2) number of barriers (sum of "usually makes harder" or "usually no" responses for each item).

The PEM-CY community section has been reported as having moderate to very good internal consistency for all community summary scores (Cronbach alpha ranging from 0.70 to 0.83 ; Bedell et al., 2012; Coster et al., 2011). Test-retest reliability over a one to four week period is moderate to very good for desire for change (ICC > 0.75) and excellent for the community environmental supportiveness summary score (ICC $=0.96$ ) (Coster et al., 2011). Moderate to strong concurrent validity of the PEM-CY number of supports $(r=-0.44, p<.05)$, and number of barriers $(r=0.58, p<.01)$ has also been established (Khetani et al., 2014).

\section{Data Collection}

For Phase One (quan) (March through June 2012), a consent form, demographic questionnaire, and PEM-CY were administered to each participant. Upon survey completion, participants were issued $\$ 10$ gift cards and entered into a drawing for an iPod Touch.

\section{Statistical Analysis}

Phase One (quan) data analysis was completed using IBM SPSS 20.0. Descriptive statistics were used to summarize sample characteristics and PEM-CY results. Since the partnering agency provides community-based programs and services, we anticipated that their staff would be best prepared to interpret and apply data from the PEM-CY community section. For this reason, only those data from the PEM-CY community section were analyzed to answer Phase One (quan) research questions.

\section{Development of Phase 2 Materials}

Phase One (quan) results informed the development of PEM-CY case reports for Phase Two (QUAL) data collection. In order to examine the extent to which agency staff can use the PEM-CY results to meet the most pressing needs of their clients, PEM-CY case reports were selected to reflect the most commonly reported functional problems of the children sampled and the most commonly reported areas of community participation restriction. Four cases were selected based on the 
following criteria: (1) the parent had reported a desire for change in at least four of the top five community activities in which all parents who were sampled in Phase One had desired change; (2) the child was identified as having "big problems" in four of the most commonly reported areas of functional difficulty for the entire study sample; and (3) complete data were available on the variables of interest. These four cases also differed according to the child's age (5-11,12-17) and gender (male, female). Prior research suggests that the child's age and gender are correlates of participation difficulty among children with disabilities (King et al., 2003a; Shikako-Thomas et al., 2008), so cases differing according to these two factors were expected to further enable transferability of Phase Two (QUAL) study results.

\section{Phase 2: Qualitative Component}

\section{Participants}

The agency Director led participant recruitment for Phase Two data collection. All participants were able to read and speak English and self-identified as a current employee.

\section{Data Collection}

An IRB amendment was approved prior to undertaking Phase Two (QUAL) data collection. Between October 2012 and February 2013, staff completed 60-min individual or dyadic semi-structured interviews in a private room at the agency. All interviews were (1) conducted by the second author using an interview guide and four PEM-CY case reports, (2) audiotaped, and (3) transcribed verbatim. The interview guide was first piloted with a respite care provider to ensure clarity and feasibility of conducting Phase Two data collection. Interview questions were refined and probes were added based on several rounds of transcript review to increase the likelihood of reaching data saturation with respect to the Phase Two (QUAL) research question (Creswell, 2011). This iterative review process resulted in a final interview guide after five out of seven staff had been interviewed. See Appendix for the final interview guide and sample PEM-CY case report.

\section{Data Analysis}

All interview data were content coded to the main questions on the final interview guide. We ensured credibility and dependability of Phase Two findings and used self-reflexivity to ensure authenticity (Creswell \& Clark 2011; Ivankova et al., 2006; Lincoln \& Guba, 1985).

\section{Credibility}

Credibility was ensured through data triangulation, which occurred by using multiple sources of information including: (a) transcripts for each interview, (b) field notes to document clarification needed for subsequent interviews and interview protocols, and c) two researchers with different disciplinary backgrounds (occupational therapy, child development) to review and interpret data (Creswell, 2007). All initial interviews used two out of four PEM-CY case reports. Preliminary results were then confirmed and disconfirmed via 30-40 min follow-up interviews with five agency staff using the remaining two PEM-CY case reports. Follow-up 
interviews were audiotaped, transcribed, and coded to check if staff members could apply preliminary results to new cases. In addition, 43 occupational therapy graduate students served as key informants and confirmed and disconfirmed preliminary results in one of two 30-min focus groups as part of their regularly scheduled class time. Key informants were selected based on their expertise and professional commitment to the topic based on their program of study.

\section{Dependability}

Interviews were initially coded by two separate staff using analytical deductive coding techniques, in which codes were established prior to data analysis and each transcript was then analyzed by searching for the presence of one or more codes. Inter-coder agreement of $94.3 \%$ was achieved by the third interview, after which the second author independently coded the remaining four interviews. Two coding reports were submitted for review and feedback by the first author to increase the likelihood of reaching data saturation with respect to the main research question(s).

\section{Self-Reflexivity}

Self-reflexivity in qualitative research involves acknowledgement and reflection by the researcher on how their experiences and understandings impact the study, which in turn provides authenticity and trustworthiness to the findings (Creswell, 2007). The second author led Phase Two data collection. Her prior experience as a special education teacher has instilled in her a value of full inclusion and the need for systematic and feasible assessment processes to diagnose and intervene with children in the school setting. During this study, the second author was concurrently employed by an assistive technology resource center on a university campus. This job demanded of her a heightened sensitivity to technological factors impacting children's participation in school and community activities. This sensitivity, in turn, may have led her to probe about assistive technology as a modifiable factor impacting participation, resulting in fewer opportunities for staff to consider other dimensions of a child's environment that were assessed for in the PEM-CY.

\section{RESULTS}

\section{Phase 1: Quantitative Findings}

\section{Child and Family Characteristics}

Twenty-three families (33.8\% of the organization's Spring 2012 enrollment) completed the PEM-CY (see Table 1). Most respondents were mothers $(90.9 \%)$ and married $(87.0 \%)$. More than half of the children sampled were male $(69.8 \%)$ and between 7 and 17 years old (mean $=10.7, S D=3.42)$. The four most commonly reported functional problems among the children sampled were: (1) paying attention or concentrating $(60.9 \%)$; (2) remembering new information (e.g., directions; $56.5 \%)$; (3) learning new information (47.8\%; and (4) communicating with others $(47.8 \%)$. 
TABLE 1. Phase One Sample Characteristics $(n=23)$

\begin{tabular}{|c|c|c|c|}
\hline Factor & Variable & Response & $N(\%)$ \\
\hline \multirow[t]{24}{*}{ Family } & Marital status & & \\
\hline & & Married & $20(87.0)$ \\
\hline & & Divorced & $1(4.3)$ \\
\hline & & Separated & $1(4.3)$ \\
\hline & & Domestic Partner & $1(4.3)$ \\
\hline & Annual income & & \\
\hline & & Less than $\$ 10,000$ & $2(8.7)$ \\
\hline & & $10-49,999$ & $4(17.4)$ \\
\hline & & $50-89,999$ & $6(26.1)$ \\
\hline & & $90-99,999$ & $4(17.4)$ \\
\hline & & Greater than $\$ 100,000$ & $7(30.4)$ \\
\hline & Respondent age (years) & & \\
\hline & & 30-39 & $4(18.2)$ \\
\hline & & $40-49$ & $16(72.7)$ \\
\hline & & $50-59$ & $2(9.1)$ \\
\hline & Respondent education & & \\
\hline & & High school or less & $3(13)$ \\
\hline & & Some college or technical training & $4(17.4)$ \\
\hline & & Graduated college/university & $9(39.1)$ \\
\hline & & Graduate degree & $7(30.4)$ \\
\hline & Children living at home & & \\
\hline & & 1 & $6(26.1)$ \\
\hline & & 2 & $11(47.8)$ \\
\hline & & 3 or more & $6(26.1)$ \\
\hline \multirow[t]{32}{*}{ Child } & Diagnosis* & & \\
\hline & & Developmental delay & $12(52.2)$ \\
\hline & & Intellectual disability & $12(52.2)$ \\
\hline & & Hearing impairment & $1(4.3)$ \\
\hline & & Speech/language impairment & $10(43.5)$ \\
\hline & & Vision impairment & $3(13.0)$ \\
\hline & & Emotional impairment & $2(8.7)$ \\
\hline & & Orthopedic impairment & $2(8.7)$ \\
\hline & & Autism spectrum disorder & $9(39.1)$ \\
\hline & & Attention deficit disorder & $6(26.1)$ \\
\hline & & Learning disability & $1(4.3)$ \\
\hline & & Health impairment & $4(17.4)$ \\
\hline & & Multiple disabilities & $2(8.7)$ \\
\hline & & Other & $5(21.7)$ \\
\hline & School placement & & \\
\hline & & Regular classroom & $4(17.4)$ \\
\hline & & Regular and special education class & $14(60.9)$ \\
\hline & & Special education class & $3(13.0)$ \\
\hline & & Other & $2(8.7)$ \\
\hline & Functional problems** & & \\
\hline & & Paying attention or concentrating & $14(60.9)$ \\
\hline & & Remembering information & $13(56.5)$ \\
\hline & & Learning new information & $11(47.8)$ \\
\hline & & Communicating with others & $11(47.8)$ \\
\hline & & Reacting to sensations & $7(30.4)$ \\
\hline & & Using his or hands & $4(17.4)$ \\
\hline & & Managing emotions & $5(21.7)$ \\
\hline & & Controlling behavior/activity level & $7(30.4)$ \\
\hline & & Seeing & $1(4.3)$ \\
\hline & Assistive technology use & & \\
\hline & & Yes & $9(39.0)$ \\
\hline & & No & $14(61.0)$ \\
\hline
\end{tabular}




\section{Parental Desire for Change in Child's Community Participation (quan 1)}

Nearly $58.3 \%$ of families desired some type of change in their child's community participation. More than two-thirds of parents sampled reported a desire for change in the following five activities: community events $(73.9 \%)$, organized physical activities $(73.9 \%)$, unstructured physical activities $(73.9 \%)$, classes or lessons (not school sponsored; $73.9 \%$ ), and getting together with other children in the community $(69.6 \%)$.

\section{Environmental Supports and Barriers to Children's Community Participation (quan 2)}

On an average, parents reported the presence of two to three supports and four barriers to their child's participation in community-based activities. Most frequently reported supports to children's community participation were: (1) personal transportation $(65.2 \%)$; (2) family time $(52.2 \%$; (3) equipment or supplies (e.g., sports equipment, craft supplies, etc., $43.5 \%)$; and (4) money (43.5\%). The most frequently reported barriers were the: (1) social demands of an activity $(47.8 \%)$; (2) cognitive demands of an activity (34.8\%); and (3) peer relationships $(26.1 \%)$.

\section{Phase 2: Qualitative Findings}

In this section, findings pertaining to the Phase Two (QUAL) research question and final mixed methods question (quan $>$ QUAL) are presented. Key topics and exemplars that illustrate each topic are presented (Creswell, 2007). References to participants use pseudonyms.

\section{Provider Characteristics}

Seven staff participated in this phase of study. As shown in Table 2, most staff were female $(85.7 \%), 30$ years or older $(85.7 \%)$, and with a wide range of experience working directly with children with disabilities.

\section{Utility of the PEM-CY for Collaborative Care Planning (QUAL)}

As depicted in Figure 2, staff described four steps for providers to carry out in order to synthesize and apply PEM-CY results for use in meaningful care planning with parents of children with disabilities: (1) Providers request that parents rank order those community activities in which they desire change in their child's

TABLE 2. Phase Two Sample Characteristics

\begin{tabular}{lllcc}
\hline Name* & Job Title & Gender & Years employed & Years of Experience \\
\hline Rachel & Supervisor & Female & 14 & $>15$ \\
Jaime & Coordinator & Female & 5 & $>5$ \\
Amanda & Coordinator & Female & 3 & $>5$ \\
Brandy & Coordinator & Female & 5 & $>15$ \\
Melissa & Leader & Female & $2-5$ & $<5$ \\
Richard & Leader & Male & $>15$ & $>5$ \\
Natalie & Leader & Female & $2-5$ & \\
\hline
\end{tabular}

*pseudonyms used. 


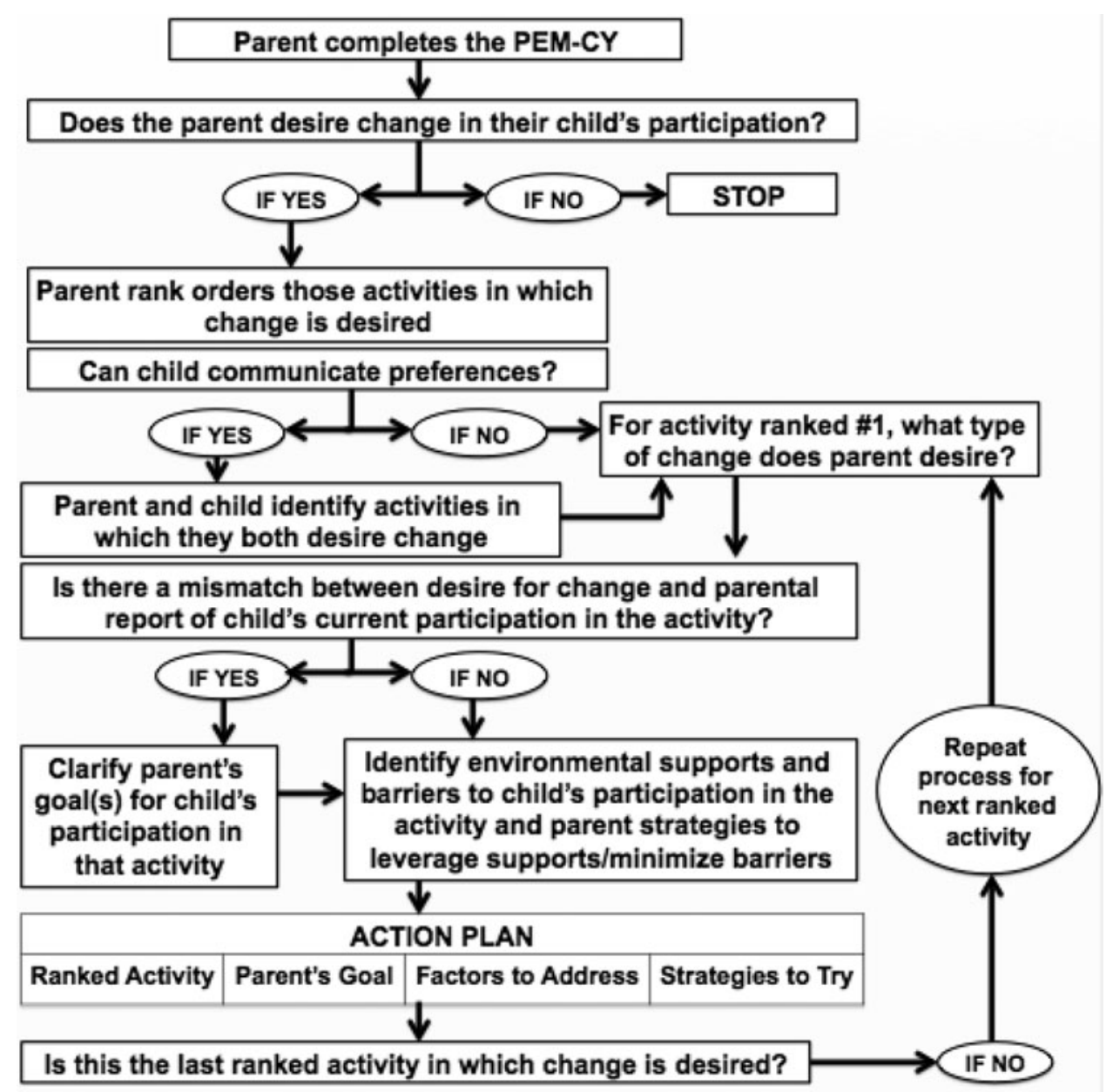

FIGURE 2. Decisional support algorithm.

community participation; (2) Providers ask that parents consider their child's capacity to communicate his or her preferences and, if so, to identify those activities in which they both desire change; (3) Providers clarify parent and child expectations for improved participation in a specific activity, particularly if parental desire for change is incongruent with the child's current level of participation; and (4) Providers ask parents to identify strategies to leverage a subset of environmental supports and minimize barriers to the child's participation in a specific activity. These four steps come together in sequence to form a decisional support algorithm for care planning in the community using the PEM-CY. In the remainder of this section, we describe each of these four steps as a separate topic.

Topic 1. Parents rank order community activities in which they desire change in their child's community participation. Six out of seven staff shared that they currently think to first ask parents about their level of satisfaction with their child's participation in different activities in order to prioritize activity(ies) to target for 
intervention planning purposes. Staff repeatedly referenced the PEM-CY results about parental desire for change as having useful information about parental satisfaction with participation. Several staff suggested that parents rank order the activity(ies) in which the parent desires change in order to prioritize the most meaningful interventions. According to Rachel, if "they [parents] had to order [activities], if they had to think about what's really important, then it may help them." Rank ordering was also perceived to be feasible to accomplish with parents during a session. Melissa shared that "rank ordering is something that you could see would be feasible to help a family figure out where to start in the process of [working toward] more participation." Rachel further elaborated on feasibility of rank ordering by highlighting ways that parents might generate a rank order of activity preferences:

They could rank order based on the child's interests. They could rank order based on what's feasible and what fits into their schedules. They may choose what their therapists want, so related to a service goal. Or they might prioritize a certain activity, like getting kids moving ...

Topic 2. Parents incorporate their child's preferences to generate a list of activities in which they both desire change. Six out of seven staff indicated the importance of considering both parent and child perspectives in the care planning process if and when possible. According to Natalie, the PEM-CY provides important information about the parent's perspective of participation-related problems, but "I think it's always important regardless of what age they are, just to try and find out what they want to do and make them part of it rather than making it seem like you are just signing them up for stuff and making them do it." Staff could not identify a specific age or skill-based cut-off for determining whether the child should be engaged in the intervention planning process, but they hypothesized that this step would become more important as the child grew older. Several participants such as Natalie recommended that the provider ask the parent to assess whether their child could communicate his or her preferences, and then consider "what they want" in "narrow[ing] it down to like three [activities] to start with" when determining a child's preferences. Brandy further emphasized the importance of this step in terms of its congruence with family-centered practice:

Definitely rank ordering is something that is feasible to help a family figure out where to start in the process of getting some more participation ... I think that any kind of intervention should be client-centered, so I think involving the child in the decision is important because they're more likely to comply than if it's just he parents saying you're going to do this.

Topic 3. Provider clarifies parent and child expectations for improved participation in a ranked activity. Five out of seven staff perceived the need to clarify the parent's goals for their child's participation in a specific ranked activity. This need arose when staff struggled to synthesize the following pieces of information from the PEM-CY case report: (1) how frequently their child participated in the activity, (2) how involved their child was when participating in the activity, and (3) the parent's desire for change in their child's participation for that activity. Two 
participants identified mismatches between the parent's desire for change and the child's current level of participation (e.g., parent wants child to do an activity more often, but child is reported as currently participating in that activity on a weekly basis). According to Brandy, “... it was important to know ... the short term goal and is that what you want to change ... do you want him involved in [this activity] seven days a week, or for one hour [on each of the] seven days a week and he's involved the entire hour ... because if he's already involved and participating, then it's like how much more do you want?" Richard suggested obtaining more information from a parent:

So, maybe for like more often, why would you want to do this activity more often? Why do you feel your child needs this more often? Is it something they are missing out on? Is it a direction that you want to sort of drive your kids towards, like I want my kid to be doing more creative, artistic things? Yeah, it would be nice to sort of know why they wanted to push their child in a certain direction.

Similarly, Melissa said that she would inquire more about this type of mismatch and provided some recommendations for how to ask parents for this type of clarification:

Well, it looks like he's doing this pretty frequently, but it sounds like you still have some concerns. What are your concerns? What do you think could be more optimal than what he's doing now? Do you want him to do it more frequently? Do you want him to ... interact with other participants more? ... like, okay, he's on the soccer team, what are you seeing that's not working right? Is he isolated from other kids? Does he not get to play frequently enough?

As illustrated, many staff indicated that having specific information from parents about their child's current participation in community activities was useful in order to identify mismatches and then clarify the most meaningful parental goals for the child.

Topic 4: Providers identify a subset of environmental supports and barriers to promote the child's participation in a ranked activity. All seven staff participants described the need to build on PEM-CY environmental results in order to identify the subset of environmental supports, barriers, and parent strategies that were impacting the child's participation in each ranked activity. By gathering additional detailed information about environmental impact at the activity level, staff felt they could identify more concrete ways to intervene. Brandy expressed the importance of "finding out what works so that you can maybe apply it to other areas" and that "any extra tips that a parent can give is huge." Similarly, Melissa emphasized the need to explicitly probe for environmental barriers by asking, "what are you seeing that's not working right [for this activity]? ... is he isolated from the other kids?"

Perceived Advantages of Integrating the PEM-CY in Care Planning Relative to Standard Practice (quan $>Q U A L$ )

All staff expressed that they would consider the PEM-CY for use in combination with their current approach to identify the most meaningful participation-related 
needs of their clients. At present, parents who enroll their child in agency services are asked questions about their child (e.g., history, disability, medical information, likes and dislikes, etc.) and then are interviewed by staff about their child's needs, class interests, accommodations, and/or environmental adaptations. Evaluations are also completed at final sessions to further assess client satisfaction with their program offerings. In relationship to their usual care planning process, five out of seven staff indicated that the PEM-CY could enhance their information gathering effort at enrollment. Rachel described how the PEM-CY provides "a more wellrounded way of getting a better answer rather than having them list off a bunch of things" and that "it would be something that could easily roll into some of our first interactions with families" and further specified that "... maybe a new family ... [you could find out] their baseline or where they're starting from, then you could start with some activities, view their progress over time, and re-do their profile at the end of the year to see their progress and what their new goals are."

It is important to note that staff consistently acknowledged that the PEM-CY report and the decisional process were both needed to obtain relevant information to help the staff progress from assessment results to a focused intervention plan with individual clients. Given the need to gather additional information, several staff acknowledged the associated costs in terms of additional staff time. In response, Melissa proposed administering a portion of the PEM-CY (e.g., community section) so that "even if a parent doesn't want to go through the process of filling out the whole thing, we can use [some of] it to kind of direct our assessment interview." Alternatively, some key informants anticipated more efficient intervention planning with the PEM-CY and decisional support algorithm over time. According to Jackie, the process forces the provider to "see the problem" and identify tangible ways to intervene, with Colleen adding, "I bet once you do it a few times, it becomes 'first nature' in how you intervene."

\section{DISCUSSION}

The importance of children's participation in community activities to promote their health and well-being (WHO, 2007) and skill development (King et al., 2003; Law et al., 2007) is well established. Service providers can play an integral part to improve children's participation given that it is a key professional task that defines their professional jurisdiction (Abbott, 1988). However, their ability to do so effectively depends on: (1) the availability of conceptually grounded and psychometrically sound assessments of children's participation (Coster \& Khetani, 2008); and (2) their ability to interpret and apply assessment results to formulate a relevant intervention plan directed towards improving participation as an outcome. The PEM-CY is the first parent-report survey to combine assessment of children's participation and environment in a single measure, and this study investigated its utility to support the care planning process.

\section{Integrating Parent and Child Priorities for Intervention}

Our findings suggest that a decisional support algorithm may be viable for use by providers to systematically interpret and apply information from a PEM-CY case report to define goals and formulate meaningful action plans in partnership with an individual client. One of the clearest steps in the algorithm relates to when and 
how providers should obtain and integrate parent and child perspectives to plan a meaningful intervention. Since the purpose of assessment guides the choice of respondent, it is not surprising that participating staff recognized the need for obtaining both parent and child perspectives early on for effective intervention planning. This finding is congruent with current standards of best practice that emphasize collaborative approaches with multiple stakeholders (Adolfsson, 2012; King et al., 2004) and prior studies about the importance of directly gathering children's perspectives (Engel-Yeger et al., 2009; Kramer \& Hammel, 2011).

Despite its importance, differences in parent and child perspectives increase as children age (Skivenes \& Strandbu, 2006), and there are challenges in how to best integrate both perspectives (Khetani et al., 2012). Depending on the child's age, disability, and/or functional abilities, Phase Two participants suggested that providers use the PEM-CY to: (1) conduct follow-up interviews with the child in order to identify those activities that are most important and problematic from the child's perspective; (2) have the child independently rank order activities on the PEM-CY in which he or she desires change; or (3) ask the parent to think about the child's preferences and interests when they rank order. These approaches are similar to those used in prior studies, such as (1) semi-structured interviews (Harding et al., 2009) or photographic methods (Kramer \& Hammel, 2011; Marley, 2012; Obrusnikova \& Cavalier, 2011) with children and youth with disabilities; or (2) comparing parent and youth self-report versions of participation measures such as the CASP (McDougall et al., 2013). Future studies should further explicate processes and approaches for integrating parent and child perspectives during care planning using the PEM-CY. Alternatively, development of a PEM-CY youth self-report may be warranted to afford for more direct comparison and integration of parent and child perspectives.

\section{Clarifying Parental Expectations and Intervention Priorities}

The PEM-CY reflects a multidimensional approach to assessment of participation by asking parents to appraise their child's frequency and involvement in activities as well as their desire for change (Coster \& Khetani, 2008; Coster et al., 2011). This assessment approach prompted most Phase Two participants to clarify parental expectations of their child's participation in order to reconcile incongruent information as reported on the PEM-CY, particularly between parental reporting of the type(s) of change desired and the child's current level of participation in that activity (e.g., a parent indicates wanting their child to participate more frequently in classes or lessons but report that the child currently participates in that type of activity a few times per week). This finding suggests that the content and layout of the PEM-CY affords providers with a window of opportunity to understand the personal meaning ascribed by parents to their child's participation in a specific type of activity. Similarly, King and colleagues (2003) found that detailed understanding of client preferences via observation or interview helped clients to develop resiliency skills that can be used to strengthen intervention planning. While all parents presumably have goals for their children's participation, these goals can vary when compared to other families, across activities and settings and over time (King et al., 2006; King, 2004; Tamis-Monda et al., 2007). Hence, continuous reassessment of 
parental goals may be needed to ensure the development of responsive interventions.

\section{Accounting for Modifiable Environmental Factors when Planning Interventions}

Service providers less often assess for environmental influences that have been shown to be associated with participation restriction (Anaby et al., 2013; Khetani et al., 2012; Law et al., 2007; Mihaylov et al., 2004). However, environments may be as amenable to change as the child's performance capacities (Law et al., 2011). Most of the Phase Two participants proposed to further build on PEM-CY case results about perceived environmental supports and barriers to identify a subset of factors that could be addressed in an action plan to achieve an activity-specific participation goal. Per Phase One results, the most frequently reported barriers to community participation were related to cognitive and social activity demands and peer relationships. There are fairly well-established methods for making these types of environmental modifications in the context of an individualized intervention. Future study with more diverse samples according to child age, family income, and geographic location may allow for greater elaboration by providers of how to engage with individual clients in developing action plans that target a broader range of environmental barriers to participation, such as community safety and peer attitudes. Commonly reported intervention strategies for addressing broader environmental barriers that are encountered by children with physical and intellectual disabilities include networking with other people, educating the social environment, advocating for the child, and creating opportunities for the child to access activities (Bedell et al., 2011; Piskur et al. 2012). Alternatively, Tseng \& Seidman (2007) suggest that systems level interventions to target broader environmental barriers that contribute to participation problems may be more appropriate.

\section{Perceived Advantages and Disadvantages of the PEM-CY for Intervention Planning}

In response to our mixed methods question, Phase Two participants in this study perceived the PEM-CY to provide a more comprehensive and consistent evaluation of their primary service outcome to facilitate intervention planning. Accessible mainstream mobile technology (e.g., iPhone, tablets, etc.) may mitigate provider concerns about the feasibility of using the PEM-CY in intervention planning with individual clients and enable the larger provider agency to aggregate PEM-CY data as part of their needs assessment to inform intervention planning for groups of clients. Wilson (2013) argues that technological advances with software and hardware development can be prominent components of change to allow for more accessible interactions between professionals and clients. A decisional support algorithm is a programmable solution to help empower parents to actively collaborate with their provider to interpret and apply their PEM-CY results for action planning purposes (Ellis \& Kent, 2011).

Results of this study should be considered in light of several limitations, some of which are opportunities for future study. First, Phase Two findings are based solely on data from the PEM-CY community section because these data were deemed by the research team to be most relevant for the intervention planning needs of our Phase Two participants. Future studies are needed to examine the usability of the decisional support algorithm when applied to PEM-CY home and school section 
results. Second, our Phase Two findings reflect only providers' perspectives about how to interpret and apply PEM-CY data. Providers are one key stakeholder in the intervention planning process, so parental perspectives of the decisional support algorithm are also needed. Subsequent studies should include multiple parental perspectives (mother, father) to examine differences according to respondent type (Jaffe et al., 2010; Thompson et al., 2013). Another potential study limitation includes active involvement of the agency director in participant recruitment for both phases of this study, which may have resulted in oversampling of active and satisfied parent and staff participants. The director's involvement, in turn, may have resulted in Phase Two participants interpreting and applying less problematic PEM$\mathrm{CY}$ case reports and generating a less viable decisional support algorithm for use by providers who struggle to systematically and/or collaboratively develop meaningful care plans with families.

\section{CONCLUSION}

Family-centered care demands active and sustained engagement of service providers with clients and family members for meaningful planning, delivery, and evaluation of quality care. This study contributes to a growing body of literature about how to assess and intervene directly on participation as an outcome for children with disabilities (Darrah et al., 2011; Palisano et al., 2012). Community-based service providers in our study identified potential advantages to using the PEM-CY in practice and proposed a stepwise process to support its use in care planning with families. We are now gathering parental perspectives to determine the usability of this decisional support algorithm as well as suitable and feasible methods to uptake this process in practice.

\section{ACKNOWLEDGMENTS}

We thank Renee Lee, CTRS and Jenna Moriarty, CTRS for oversight of participant recruitment for this study. We also thank Jenifer Marley, Megan Baker, and Kristen Fitzgerald for data management and analytic support, and to Molly Gleason, Rachel Ohene, Xinrui Jiang, and Tanya Benjamin for their assistance with assembling tables, figures, and references and for their feedback on earlier drafts of this manuscript.

Declaration of interest: The authors report no declarations of interest. The authors alone are responsible for the content and writing of this article.

This study was funded by the Department of Occupational Therapy, Colorado State University and was completed in partial fulfillment of the M.S. degree in Occupational Therapy (Cliff).

\section{ABOUT THE AUTHORS}

Mary A. Khetani, Department of Occupational Therapy, Colorado State University, Fort Collins, CO, USA. Anna B. Cliff, Department of Occupational Therapy, Colorado State University, Fort Collins, CO, USA. Cathy Schelly, Department of Occupational Therapy, Colorado State University, Fort Collins, CO, USA. Lisa 
Daunhauer, Department of Human Development and Family Studies, Colorado State University, Fort Collins, CO, USA. Dana Anaby, School of Physical and Occupational Therapy, McGill University, Montreal, Quebec, Canada.

\section{REFERENCES}

Abbott A. (1988). The system of professions: An essay on the division of expert labor. Chicago, IL: University of Chicago Press.

Adolfsson M. (2012). Applying the ICF-CY to identify children's everyday life situations: A step towards participation-focused code sets. International Journal of Social Welfare 22:195-206.

Anaby D, Hand C, Bradley L, DiRezze B, Forhan M, DiGiacomo A, Law M. (2013). The effect of the environment on participation of children and youth with disabilities: A scoping review. Disability \& Rehabilitation 35:1589-1598.

Barnett A, Dawes H, Wilmut K. (2012). Constraints and facilitators to participation in physical activity in teenagers with developmental coordination disorder: An exploratory interview study. Child: Care, Health and Development 39(3):393-403.

Bedell, G, Coster W. (2008). Measuring participation of school-aged children with traumatic brain injuries: Considerations and approaches. Journal of Head Trauma Rehabilitation 23:220-229.

Bedell G, Coster WJ, Law M, Liljenquist K, Kao Y-C, Teplicky R, Anaby D, Khetani MA. (2012). Community participation, supports and barriers of school age children with and without disabilities. Archives of Physical Medicine and Rehabilitation 94(2):315-323.

Bedell G, Khetani M, Cousins M, Coster WJ, Law M. (2011). Parent perspectives to inform development of measures of children's participation and environment. Archives of Physical Medicine and Rehabilitation 92(5):765-773.

Bronfenbrenner U. (1977). Toward an experimental ecology of human development. American Psychologist 32(7):513-531.

Coster W, Bedell G, Law M, Khetani MA, Teplicky R, Liljenquist K, et al. (2011). Psychometric evaluation of the participation and environment measure for children and youth. Developmental Medicine \& Child Neurology 53(11):1030-1037.

Coster W, Khetani MA. (2008). Measuring participation of children with disabilities: Issues and challenges. Disability \& Rehabilitation 30(8):639-648.

Coster W, Law M, Bedell G, Khetani M, Cousins M, Teplicky R. (2012). Development of the participation and environment measure for children and youth: Conceptual basis. Disability and Rehabilitation 34(3):238-246.

Creswell JW. (2007). Qualitative inquiry \& research design: Choosing among five approaches ( 2 ed.). Thousand Oaks, CA: Sage Publications, Inc.

Creswell JW, Clark VLP. (2011). Designing and conducting mixed methods research (2 ed.). Thousand Oaks, CA: SAGE Publications, Inc.

Darrah J, Law MC, Pollock N, Wilson B, Russell DJ, Walter SD, .. Galuppi B. (2011). Context therapy: A new intervention approach for children with cerebral palsy. Developmental Medicine \& Child Neurology 53(7):615-620.

Dunst CJ, Hamby D, Trivette CM, Raab M, Bruder MB. (2002). Young children's participation in everyday family and community activity. Psychological Reports 91(3):875-897.

Ellis K, Kent M. (2011). Disability and new media. New York, NY: Taylor \& Francis.

Engel-Yeger B, Jarus T, Anaby D, Law M. (2009). Differences in patterns of participation between youths with cerebral palsy and typically developing peers. American Journal of Occupational Therapy 63(1):96-104.

Harding J, Harding K, Jamieson P, Mullally M, Politi C, Wong-Sing E., et al. (2009). Children with disabilities' perceptions of activity participation and environments: A pilot study. Canadian Journal of Occupational Therapy 76:133-144.

Ivankova NV, Creswell JW, Stick SL. (2006). Using mixed-methods sequential explanatory design: From theory to practice. Field Methods 18(1):3-20.

Jaffe L, Humphry R, Case-Smith J. (2010). Working with families. In J. Case-Smith \& J. C. O'Brien (Eds.), Occupational therapy for children (6 ed., pp. 108-140). Maryland Heights, MO: Mosby Elsevier. 
Khetani MA, Bedell G, Coster W, Cousins M, Law M. (2012). Environmental factors: Physical, social, and attitudinal environment (e110-e165, e210-e260, e310-e360, e410-e465, e510-e591). In Majnemer, A, ed., Measures for children with developmental disabilities: An ICF-CY approach. London: Mac Keith Press, 440-454.

Khetani MA, Marley J, Baker M, Albrecht E, Bedell G, Coster W. et al. (2013). Validity of the participation and environment measure for children and youth (PEM-CY) for health impact assessment (HIA) in sustainable development projects. Disability and Health Journal. doi: http://dx.doi.org/10.1016/j.dhjo.2013.11.003

King GA. (2004). The meaning of life experiences: Application of a metamodel to rehabilitation sciences and services. American Journal of Orthopsychiatry 74(1):72-88.

King GA, Brown EG, Smith LK. (2003a). Resilience: Learning from people with disabilities and turning points in their lives. Westport, CT: Praeger Publishers.

King GA, Law M, Hanna S, King S, Hurley P, Rosenbaum P, et al. (2006). Predictors of the leisure and recreation participation of children with physical disabilities: a structural equation modeling analysis. Children's Health Care 35(3):209-234.

King GA, Law M, King S, Rosenbaum P, Kertoy MK, Young NL. (2003b). A conceptual model of the factors affecting the recreation and leisure participation of children with disabilities. Physical \& Occupational Therapy in Pediatrics, 23(1):63-90.

King M, Shields N, Imms C, Black M, Ardern C. (2013). Participation of children with intellectual disability compared with typically developing children. Research in Developmental Disabilities 34(5):1854-1862.

King S, Teplicky R, King G, Rosenbaum P. (2004). Family-centered service for children with cerebral palsy and their families: A review of the literature. Paper presented at the Seminars in pediatric neurology 11(1):78-86.

Kramer JM, Hammel J. (2011). "I do lots of things": Children with cerebral palsy's competence for everyday activities. International Journal of Disability, Development and Education 58(2):121-136.

Law M, Anaby D, Teplicky R, Khetani MA, Coster W, Bedell G. (2013). Participation in the home environment among children and youth with and without disabilities. The British Journal of Occupational Therapy 76(2):58-66.

Law M, Cooper B, Strong S, Stewart D, Rigby P, Letts L. (1996). The person environmentoccupation model: A transactive approach to occupational performance. Canadian Journal of Occupational Therapy, 63(1):9-23.

Law M, Darrah J, Pollack N, Wilson B, Russell DJ, Walter SD, et al. (2011). Focus on function: A cluster, randomized controlled trial comparing child versus context-focused intervention for young children with cerebral palsy. Developmental Medicine \& Child Neurology 53(7):621-629.

Law M, Petrenchik T, King G, Hurley P. (2007). Perceived environmental barriers to recreational, community, and school participation for children and youth with physical disabilities. Archives of Physical Medicine and Rehabilitation 88(12):1636-1642.

Lincoln YS, Guba E. G. (1985). Naturalistic inquiry. Beverly Hills, CA: SAGE Publications.

Marley J. (2012). Photovoice for post-occupancy evaluation: Students explore health in a sustainable school. Proquest: Dissertations \& Theses. Retrieved April 30, 2013 from http:// ezproxy2.library.colostate.edu:2057/dissertations/docview/1038960986/13DD24BDD5311C14 B2A1/2? accountid $=10223$

McDougall J, Bedell G, Wright V. (2013). The youth report version of the Child and Adolescent Scale of Participation (CASP): assessment of psychometric properties and comparison with parent report. Child: Care, Health and Development 39(4):512-522.

McIntyre S, Novak I, Cusick A. (2010). Consensus research priorities for cerebral palsy: A delphi survey of consumers, researchers, and clinicians. Developmental Medicine \& Child Neurology 52(3):270-275.

Mihaylov SI, Jarvis SN, Colver AF, Beresford,B. (2004). Identification and description of environmental factors that influence participation of children with cerebral palsy. Developmental Medicine \& Child Neurology 46(5):299-304.

Obrusnikova I, Cavalier AR. (2011). Perceived barriers and facilitators of participation in afterschool physical activity by children with autism spectrum disorders. Journal of Developmental and Physical Disabilities 23(3):195-211. 
Palisano RJ, Chiarello LA, King GA, Novak I, Stoner T, Fiss A. (2012). Participation-based therapy for children with physical disabilities. Disability and Rehabilitation 34(12):1041-1052.

Piškur B, Beurskens AJ, Jongmans MJ, Ketelaar M, Norton M, Frings CA, et al. (2012). Parents' actions, challenges, and needs while enabling participation of children with a physical disability: A scoping review. BMC Pediatrics 12(1):177. doi:10.1186/1471-2431-12-177.

Rogoff B. (2003). The cultural nature of human development. Oxford University Press.

Shikako-Thomas K, Majnemer A, Law M, Lach L. (2008). Determinants of participation in leisure activities in children and youth with cerebral palsy: systematic review. Physical \& Occupational Therapy in Pediatrics 28(2):155-169.

Skivenes M, Strandbu A. (2006). A child perspective and children's participation. Children Youth and Environments 16(2):10-27.

Tamis-Monda CS, Way N, Hughes D, Yoshikawa H, Kalman RK, Niwa EY. (2007). Parents' goals for children: the dynamic coexistence of individualism and collectivism in cultures and individuals. Social Development 17(1):183-209.

The United Nations Children's Fund (UNICEF) (2013). The state of the world's children. Retrieved May 3, 2013 from: http://www.unicef.org/sowc2013/files/SWCR2013_ENG_Lo_res_ 24_Apr_2013.pdf

Thompson S, Hiebert-Murphy D, Trute B. (2013). Parental perceptions of family adjustment in childhood developmental disabilities. Journal of Intellectual Disabilities 17(1):24-37.

Tseng V, Seidman E. (2007). A systems framework for understanding social settings. American Journal of Community Psychology 39(3-4):217-228.

Verschuren O, Wiart L, Ketelaar M. (2013). Stages of change in physical activity behavior in children and adolescents with cerebral palsy. Disability \& Rehabilitation 35(19):1630-1635.

Whiteneck G, Dijkers MP. (2009). Difficult to measure constructs: Conceptual and methodological issues concerning participation and environmental factors. Archives of Physical Medicine and Rehabilitation 90(11):S22-S35.

WHO (2007). International classification of functioning, disability and health: Children and youth version (ICF-CY). Geneva, Switzerland: World Health Organization Press, WHO.

Wilson P. (2013). Iphone and ipod touch apps-childhood disability. Retrieved April 29, 2013, from http://www.bellaonline.com/articles/art62136.asp.

World Health Organization \& The World Bank (2011). World Report on Disability. WHO Library Cataloguing-in-Publication Data. Retrieved May 5, 2013 from: http://whqlibdoc. who.int/publications/2011/9789240685215_eng.pdf

United Nations (2006). Convention on the rights of persons with disabilities. Retrieved November 5, 2013 from http://www.un.org/disabilities/convention/conventionfull.shtml

\section{APPENDIX}

\section{PEM-CY Case Report and Phase Two Interview Guide}

\section{Tim's Profile:}

Tim is a 12-year-old, Caucasian boy who has lived in Fort Collins for 2 years and Colorado his entire life. Tim's mother indicates that he has health problems or disabilities, which include orthopedic impairment/movement impairment (mild hypotonic) and autism spectrum disorder. Tim's mother also noted that he experiences "big problems" or difficulties in the following areas: paying attention or concentrating, remembering information, (e.g., directions), learning new information or new activities, communicating with others, reacting to sensations, managing emotions (e.g., anxiety), and controlling behavior or activity level. At school, Tim attends both a regular and special education classroom. He currently uses assistive technology, which his mother does not know the name, but stated it is a "computer with a program on it." 
Tim's Family profile:

Tim lives with his mother who is in her 40 s and earns more than $\$ 100,000$ a year. Tim's mother has completed some college/university training.

\section{Tim's Involvement in ARO Services:}

Tim began accessing services at ARO about 2 months ago and participates in services about 1 time per week. He participates in aquatics, swim, and aqua fitness. Tim's mother said that participation in ARO services was a 10 out of 10 , meaning they were extremely important to her and Tim. Tim's mother also indicated they were 10 out of 10 with satisfaction meaning she was extremely satisfied with Tim's participation in services.

Tim's Participation Profile:

Here, we show you those community activities Tim's mother wants his participation to change and what type of change.

\begin{tabular}{|c|c|c|c|c|c|}
\hline & $\begin{array}{l}\text { Do more } \\
\text { often }\end{array}$ & $\begin{array}{l}\text { Do less } \\
\text { often }\end{array}$ & $\begin{array}{l}\text { Be more } \\
\text { involved }\end{array}$ & $\begin{array}{l}\text { Be less } \\
\text { involved }\end{array}$ & $\begin{array}{c}\text { Be involved in a } \\
\text { broader variety } \\
\text { of activities }\end{array}$ \\
\hline Neighborhood outings & $\mathrm{x}$ & & $\mathrm{x}$ & & $x$ \\
\hline Community events & $\mathrm{x}$ & & $\mathrm{x}$ & & \\
\hline Organized physical activities & $\mathrm{x}$ & & $\mathrm{x}$ & & \\
\hline Unstructured physical activities & $x$ & & $x$ & & \\
\hline $\begin{array}{l}\text { Classes or lessons (not } \\
\text { school-sponsored) }\end{array}$ & $x$ & & $x$ & & \\
\hline $\begin{array}{l}\text { Organizations, groups, clubs, and } \\
\text { volunteer or leadership activities }\end{array}$ & $x$ & & $x$ & & $x$ \\
\hline Getting together with other children & $x$ & & $x$ & & \\
\hline Working for pay & $\mathrm{x}$ & & $\mathrm{x}$ & & \\
\hline
\end{tabular}

Here, we show you how often Tim actually participates in the eight activities that his mother wants to see change.

\section{How often Tim Participates in Activities in which his Mother Wants Change}

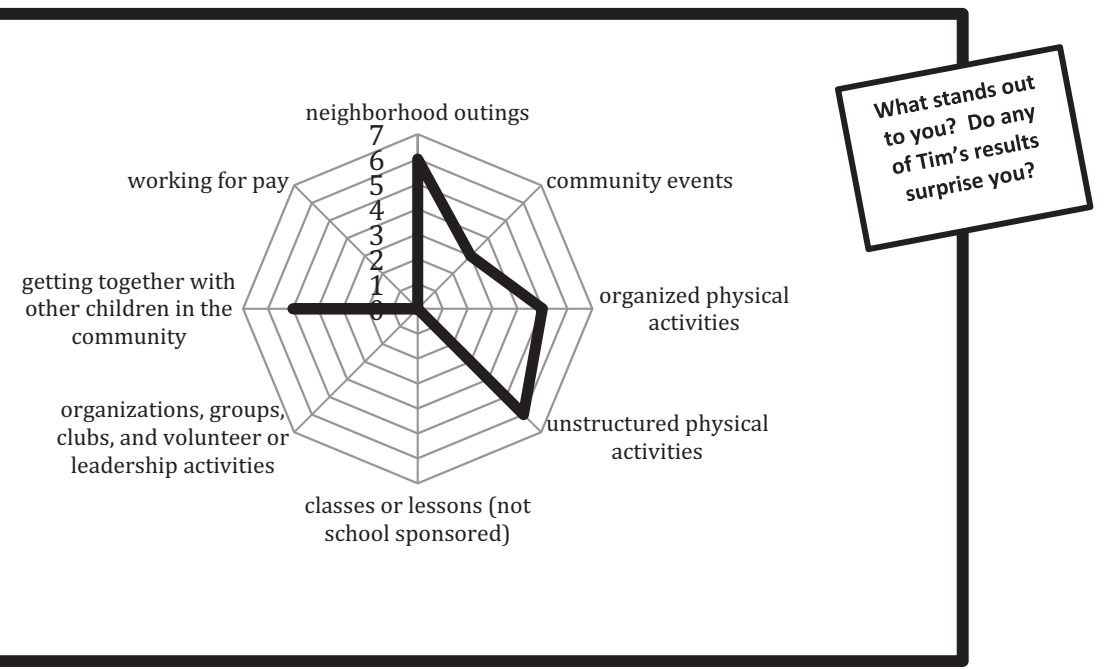

Frequency of participation was rated on a scale of 0 to 7 
$(0=$ Never, $2=$ few times in last 4 months, $3=$ once a month, $6=$ few times a week, 7 = Daily)

Lastly, we show you what Tim's involvement looks like in the eight activities that his mother wants to see change.

Tim's Involvement in Activities in which his Mother Wants Change

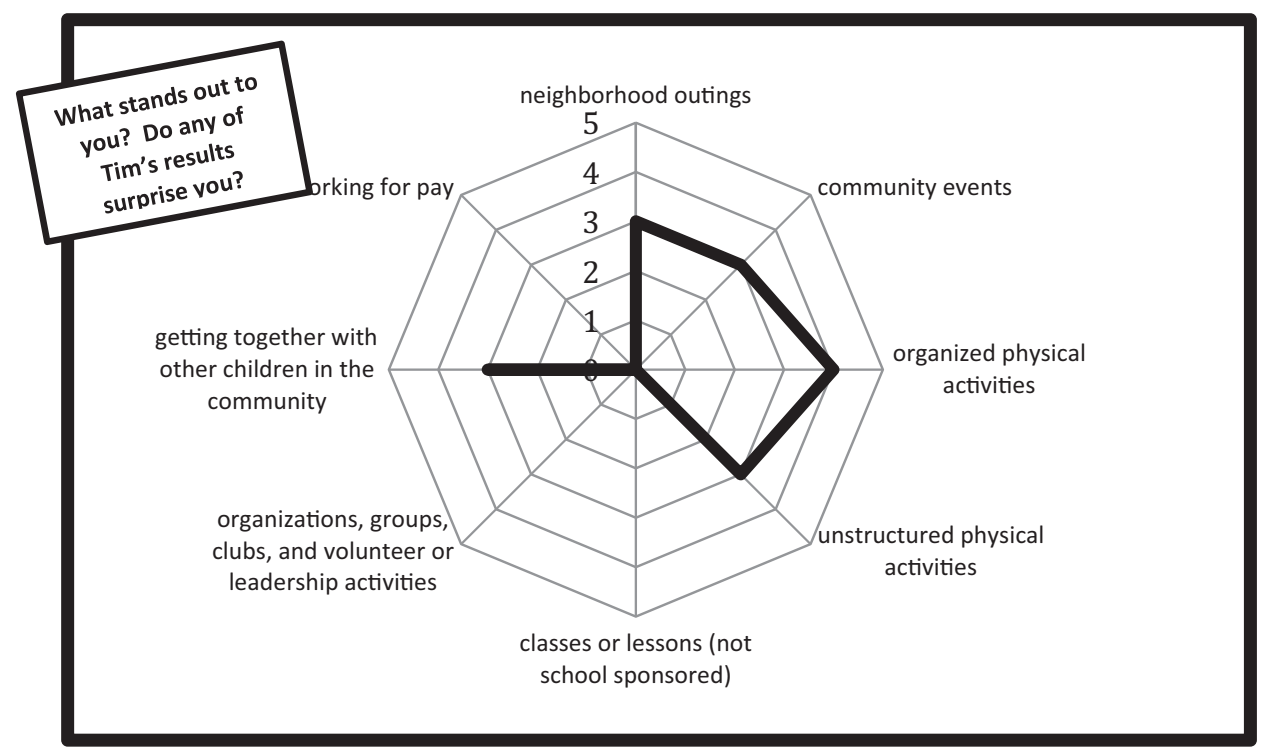

Level of Involvement was rated on a scale of 1 to 5

$(1=$ Minimally Involved, $3=$ somewhat involved, $5=$ Very Involved

\section{Supports and Barriers to Tim's Participation:}

Here, we show what Tim's mother perceives to be supports and barriers to his participation in community-based activities.

\begin{tabular}{|c|c|c|c|c|}
\hline & $\begin{array}{c}\text { Not an issue/ } \\
\text { not needed }\end{array}$ & $\begin{array}{c}\text { Usually helps/ } \\
\text { usually, yes }\end{array}$ & $\begin{array}{c}\text { Sometimes helps; } \\
\text { sometimes makes } \\
\text { harder/sometimes } \\
\text { no }\end{array}$ & $\begin{array}{c}\text { Usually makes } \\
\text { harder/ usually, } \\
\text { no }\end{array}$ \\
\hline Physical layout & & & $x$ & \\
\hline Sensory qualities & & & & $x$ \\
\hline Physical demands & & & $\mathrm{x}$ & \\
\hline Cognitive demands & & & & $\mathrm{x}$ \\
\hline Social demands & & & & $\mathrm{x}$ \\
\hline Peer relationships & & & $\mathrm{x}$ & \\
\hline Attitudes of others & & & $\mathrm{x}$ & \\
\hline Weather conditions & & & $\mathrm{x}$ & \\
\hline Safety & & & $\mathrm{x}$ & \\
\hline Personal transportation & & $x$ & & \\
\hline Public transportation & $x$ & & & \\
\hline Programs/services & & & $\mathrm{x}$ & \\
\hline Information & & & $\mathrm{x}$ & \\
\hline Equipment or supplies & & $\mathrm{x}$ & & \\
\hline Family time & & $\mathrm{x}$ & & \\
\hline Family money & & $\mathrm{x}$ & & \\
\hline
\end{tabular}


Additional strategies that Tim's mother uses to support community participation:

1. Talk about what to expect

2. Adapt activities as needed

3. Coach others on our needs

\section{Phase 2 Final Interview Guide}

$Q U A L$

1. First we give you a snapshot of the areas where change is most desired. When you look at this table, in which activities does this parent want change?

2. Select activities on this table that you currently have programming for. For each activity:

a. What types of change does this parent want for their child?

Probe: Is it clear to you what more often and more involvement mean when desired? If not, how could you get this information?

Probe: Some of your peers have noticed that there are sometimes mismatches between the frequency and involvement in the radar plots. Does this make sense to you that there would be a mismatch? If so, how do you explain it? If not, how could you get a better understanding of this from the parent?

b. Do you think that it is helpful to know about the specific types of change that parents want for their child? If so, please explain.

c. What types of things do you think are associated with reduced participation in this activity?

Probe: There is one chart that lists features of the environment that are supports and barriers for this child. Is this information helpful to how you would support a child in your classes?

Probe: Do you use the diagnosis of a child or the disability to help inform what programs and services the child may need or want?

(quan $>Q U A L)$

1. What is your current process for supporting families of children with disabilities in your classes and programs (e.g., phone conversations, paperwork from families, participant forms, etc.)

2. After reviewing the general summary and the individual case studies, what do you see as the advantages and disadvantages of using the PEM-CY?

Probe: Do you think you could use it with an individual family? Let's say this child is new to your class and the parent filled out the PEM-CY. How does this fit into your current process? Is it similar, different, and how? 